\title{
Variability of Crude Palm Oil Acidity Among Individual Oil Palm (Elaeis Guineensis Jacq.) Progenies of La Dibamba Germplasm
}

\author{
Likeng Li Ngue Benoit Constant ${ }^{1,2 *}$, Ngalle Bille Hermine ${ }^{1}$, Nsimi Mva Armand ${ }^{1}$, Ntsomboh Ntsefong \\ Godswill ${ }^{1,2}$, Limala II Etienne Pacôme ${ }^{1}$ and Bell Joseph Martin ${ }^{1}$
}

${ }^{1}$ Laboratory of Genetics and Plant Improvement, University of Yaounde, Department of Plant Biology, Yaounde-Cameroon

${ }^{2}$ Lipids Analysis Laboratory, IRAD Specialized Centre for Oil Palm Research of La Dibamba, Douala-Cameroon

*Corresponding author: Likeng Li Ngue Benoit Constant, Laboratory of Genetics and Plant Improvement, University of Yaounde, Department of Plant Biology, Yaounde-Cameroon.

Received Date: January 22, 2020

Published Date: January 28, 2020

\begin{abstract}
Crude palm oil (CPO) from the mesocarp of oil palm (Elaeis guineensis Jacq.) fruits is one of the most consumed vegetable oils in the world. The free fatty acids (FFA) content of CPO determine its dietary quality. The objective of this study was to determine the variability of acid value of CPO among La Dibamba germplasm in order to identify progenies that produce oil with low acid value. Crude palm oil acidity was analyzed according to AFNOR procedure. Results show that there is a wide variability of oil acidity within and between progenies. The different acidity values obtained from 204 trees analyzed were classified as low $(8.82 \%)$, average $(14.21 \%)$ and high $(77.45 \%)$. Analysis of these results suggests the possibility of breeding to improve the quality of palm oil by exploiting progenies that produce low acidity oil..
\end{abstract}

Keywords: Elaeis guineensis Jacq.; Genetic variability; Palm oil acidity; Genotype

\section{Introduction}

Crude palm oil (CPO) from the mesocarp of the oil palm (Elaeis guineensis Jacq.) fruit is the most produced vegetable oil in the world. In 2015, CPO consumption was estimated at 35\% [1]. In Cameroon, $70 \%$ of $\mathrm{CPO}$ is produced by agro-industries while $30 \%$ is produced by the informal sector (smallholders). Oil from informal sector represents almost $90 \%$ of the locally consumed vegetable oil in Cameroon [2]. CPO is mainly composed of triglycerides or triacylglycerols which represent $95 \%$ of all constituents and minor compounds such as diacylglycerol, mono glycerol and free fatty acids (about 5\% FFA) issued from the biosynthesis and / or hydrolysis of triacylglycerols. Sterol, tocopherol, pigments and metal ions are also present in CPO [3,4]. The fatty acids present in CPO vary with number of carbon atoms ranging from 14 to 20 . They include saturated fatty acids such as myristic acid (C14:0), palmitic acid (C16:0), stearic acid (C18:0), and arachidic acid (C20:0). Monounsaturated fatty acids included are palmitoleic acid (C16:1), oleic acid (C18:1) and polyunsaturated fatty acids include linoleic acid (C18:2) and linolenic acid (C18:3). In terms of proportions, palmitic acid is the major saturated fatty acid while the main unsaturated fatty acid is oleic acid. Ranges of fatty acids contained in CPO are as follows: myristic acid (0.9 - 2\%), palmitic acid (39.2 - 45.8\%), palmitoleic acid (0 - 0.4\%), stearic acid (3.7 - 6\%), oleic acid (37.4 - 44.1\%), linoleic acid (8.7 - 12.5\%), linolenic acid (0 $0.6 \%)$ and arachidic acid (0-0.4\%) [3-5].

CPO quality is mainly evaluated on the basis of impurities and its acidity which is an indicator of free fatty acids (FFA) content $[6,7]$. The presence of FFA in palm oil indicates the level of oil degradation during extraction and storage. If the FFA content is high, this indicates that the fruits were damaged between harvest and extraction or harvested fruits were over-ripe [7]. Therefore, high values of acidity due to lipase activity is an indication of oil quality impairment. Without refining, such oil may be unsuitable for human consumption even though refining leads to the loss of palm oil nutritional value.

Oxidation caused by light and temperature Mulindi et al. [8] is a factor that influences the organoleptic value of CPO by increasing its 
free fatty acids content. The presence of FFA in palm oil is favored by lipase activity $[9,10,7,11]$. and high-water content (when greater than $0.1 \%$ ). Smallholders usually do not consider these issues in their oil production process. It is not obvious for consumers to assess CPO quality on the market, and this is a cause for concern in terms of food security. In Cameroon for instance, analysis of CPO samples from nonindustrial oil mills Ngando et al. [12] revealed that lipid peroxidation and oil acidity increased significantly during the first four weeks of storage, making the samples unfit for consumption. In another study Ngando et al. [13] analyzed oil samples from 10 major markets in Douala and found that oil acidity values of more than $50 \%$ of the samples were above the $5 \%$ maximum limit recommended for dietary CPO. Goudoum et al. [14] also found a wide variation of FFA in CPO between $6.49 \%$ and $9.44 \%$ before storage, which increased significantly, reaching up to $16.50 \%$ FFA at $30^{\circ} \mathrm{C}$ during the first three months of storage. Gulla and Waghray [15] showed that the storage time influences oil composition in terms of FFA content. Ohimain et al. [16] on their part showed that palm oil acidity also varied from 0.97 to $8.43 \%$. Noviar et al. [17] reported that the factors raising the FFA levels above the quality standards are machine, man, management, materials and methods. According to several studies, microorganisms also contribute to lipase activity $[6,10,11,18-20]$.

It has also been demonstrated that the genotype of oil palm also determines the quality of CPO it produces [21-23]. However, to the best of our knowledge, the variability of oil acidity has not been clearly established among oil palm genitors and progenies used for improved seed production. The objective of this study was to determine the variability of CPO acidity among individual palm trees from various progenies of La Dibamba elite germplasm in view of eventually including them in the seed production program for oil quality improvement.

\section{Materials and Method}

\section{Study site}

This study was realized at La Dibamba specialized centre for oil palm research (CEREPAH) of the Institute of Agricultural Research for Development (IRAD). La Dibamba is located in the humid tropical zone with monomodal rainfall regime, in the Littoral Region of Cameroon. The Centre is found in the Mbongo-Ndonga zone at $3^{\circ} 54^{\prime} 62^{\prime \prime}$ latitude North and $9^{\circ} 51^{\prime} 77^{\prime \prime}$ latitude East, at $55 \mathrm{~m}$ asl. There are two distinct seasons at La Dibamba. The dry season runs from mid-October to mid-March while the rainy season goes from mid-March to mid-October. Rainfall is about $2500 \mathrm{~mm} /$ year and sunshine is $1400 \mathrm{~h} /$ year with an average annual temperature of $27.50^{\circ} \mathrm{C} /$ year.

\section{Plant materials}

Some 204 individual commercial seed production oil palm trees were sampled from 11 progenies, resulting from 15 parents (LM 1607P, LM 2052T, LM 2515D, LM 2749D, LM 2750D, LM 300D, LM 3034D, LM 3038D, LM 3043D, LM 3050D, LM 5100D, LM 5155D, LM
5216D, PO 2768P, PO 3281T) of some palms planted in CEREPAH of La Dibamba between 1993 and 1997. The progenies sampled are presented in Table 1.

Table 1: Female and male progenies used in this study.

\begin{tabular}{|c|c|c|}
\hline Progenies & $\begin{array}{c}\text { Role in Seed Production } \\
\text { (Parents) }\end{array}$ & Type of Cross \\
\hline LM 18175 & Female & LM 5155 D X LM 5100 D \\
\hline LM 18688 & Female & LM 2515D AF \\
\hline LM 17685 & Female & LM 3038 D X LM 3034 D \\
\hline LM 18744 & Female & LM 5216 D X LM 5100 D \\
\hline LM 19121 & Female & LM 300 D AF \\
\hline LM 17163 & Female & LM 2750 D X LM 2749 D \\
\hline LM 17204 & Female & LM 3050 D X LM 5100 D \\
\hline LM 16598 & Female & LM 3043 D X LM 3038 D \\
\hline P0 5670 & Male & PO 3281T AF \\
\hline PO 5669 & Male & PO 3281 T X PO 27 68 P \\
\hline LM 16844 & Male & LM 2052T X LM 1607 P \\
\hline
\end{tabular}

\section{Methods}

\section{Bunch harvest and oil extraction}

Matured fresh fruit bunches were harvested from open pollinated palms throughout the year. Bunch maturity was determined by the presence of two to six loose fruits [24]. One bunch was harvested from each tree and at least 8 trees were haphazardly chosen per progeny. Oil extraction was done using hexane with the Soxhlet method [22].

\section{Determination of palm oil acidity}

Palm oil acidity (POA) was analyzed on CPO from the mesocarp of ripe fruits by titration in the Lipids analysis laboratory of IRAD Dibamba as described in Likeng et al. [23] according to [25]. To homogenize our scales in the graphical representation using Microsoft Excel 2007 software, the acidity of the most acid genitor noted "a" is represented in each progeny. The different acidity values obtained were classified as low (acidity less than $5 \%$ ), average (acidity between 5 and 10\%) and high (acidity greater than $10 \%)$.

\section{Results and Discussion}

\section{Results}

An examination of acidity results obtained on oil palm progenies in CEREPAH showed that palm oil acidity of the progenies issued from the same parents could be different. This depends on the genotype and type of cross. This result confirms observations by León et al. [26] who showed that FFA of olive oil varied with the nature of cross. In an earlier study, Ngando et al. [22] also showed with the same material, that FFA content of CPO from mesocarp varies with respect to oil palm genotype (Table 2). 
Table 2: FFA contents of the mesocarp of fruits from different oil palm origins.

\begin{tabular}{|c|c|c|c|}
\hline \multirow{2}{*}{ Origin } & No & Cross & $\begin{array}{c}\text { Acidity (\% Palmitic } \\
\text { Acid) }\end{array}$ \\
\hline \multirow{4}{*}{ Déli x La Mé } & 1 & LM 2 T x DA 115 D & 24.02 \\
\cline { 2 - 4 } & 2 & LM 2 T x DA 115 D & 30.95 \\
\cline { 2 - 4 } & 3 & P0 3174 D x P0 3349 P & 7.3 \\
\hline \multirow{4}{*}{ La Mé } & 4 & P0 3281 T self & 27.63 \\
\cline { 2 - 4 } & 5 & P0 4973 T x PO 4749 P & 5.25 \\
\cline { 2 - 4 } & 6 & P0 4973 T x P0 4749 P & 23.29 \\
\cline { 2 - 4 } Yéli x & 7 & P0 3281 T & 39.6 \\
\hline \multirow{3}{*}{ Yangambi } & 8 & LM 8102 D x PO 4257 T & 24.17 \\
\hline \multirow{3}{*}{ Yangambi } & 9 & LM 8102 D x PO 4257 T & 28.56 \\
\cline { 2 - 4 } & 10 & LM 718 T self & 28.67 \\
\cline { 2 - 4 } & 11 & LM 718 T self & 17.36 \\
\cline { 2 - 4 } & 12 & P0 4257 T x PO 4260T & 36.58 \\
\hline
\end{tabular}

All the progenies of table II are used for seed production at the oil palm Specialized Research Centre of La Dibamba (Douala-Cameroon).

\section{Palm oil acidity of individual male seed production palms from different progenies}

The result of palm oil acidity from 11 analyzed trees from progeny PO 5670, showed $100 \%$ of high acidity in Mendelian inheritance with different acidity values ranging between 9.79 and $25.07 \%$ (Figure 1). Only two genitors produced oil with average acidity.

Analysis of 12 trees in progeny PO 5669 resulting from a cross between a Tenera (PO 3281T) and Pisifera (PO 2768P) parents, also showed $100 \%$ high acidity. This also represented $100 \%$ of high acidity in Mendelian inheritance. The different acidity values varied between 5.76 to $29.80 \%$ (Figure 2). Three genitors produced CPO with average acidity. Progeny LM 16844 on its part showed heterogeneity for acidity, with a sample of eight trees, four of which produced CPO with high acidity and four with low acidity. The percentages of high-acid progenitors varied between $12.20 \%$ and $19.90 \%$. Low acidity values varied between 1.24 and $1.96 \%$. This progeny is issued from the cross of a Tenera female parent (LM 2052 T) and a Pisifera male parent (LM 1607 P) (Figure 3). No genitor produced CPO with average acidity. Palm oil acidity of individual female seed production palms from different progenies

In progeny LM 19121 from the LM 3005D x LM 3005D cross, 11 trees out of 13 produced oil with a higher acidity than the standard. The proportions obtained were $84.61 \%$ for genitors with a higher acidity than the norm and $15.39 \%$ for genitors with acidity below the norm (Figure 4). Only genitors 5 and 6 produced oil with average acidity.

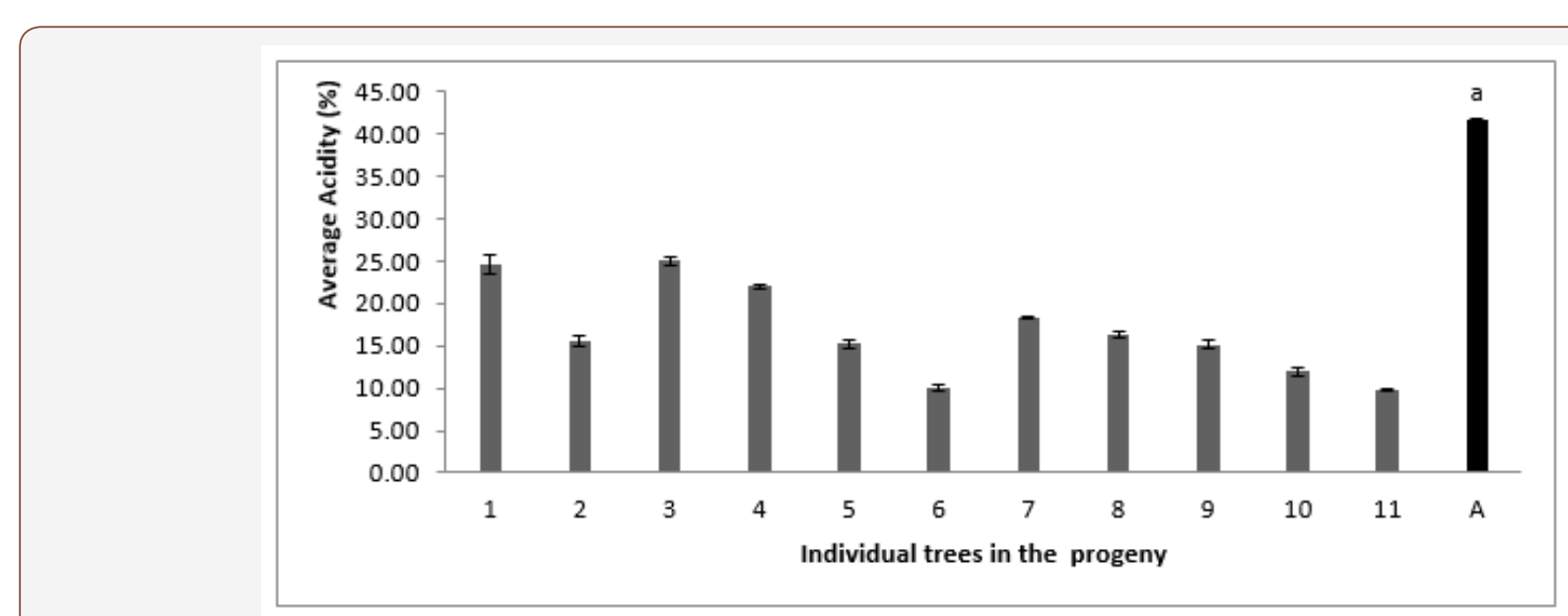

Figure 1: Location map of the study area.

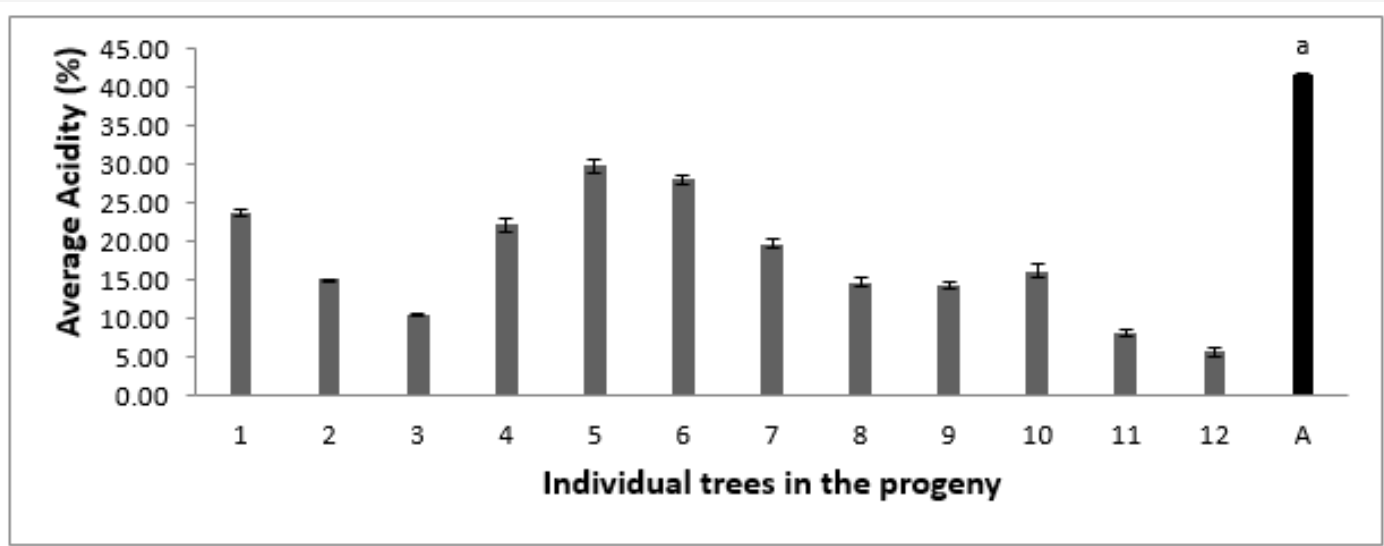

Figure 2: POA of progeny PO 5669. a: acidity of the most acid genitor in the set of genitors analyzed. 


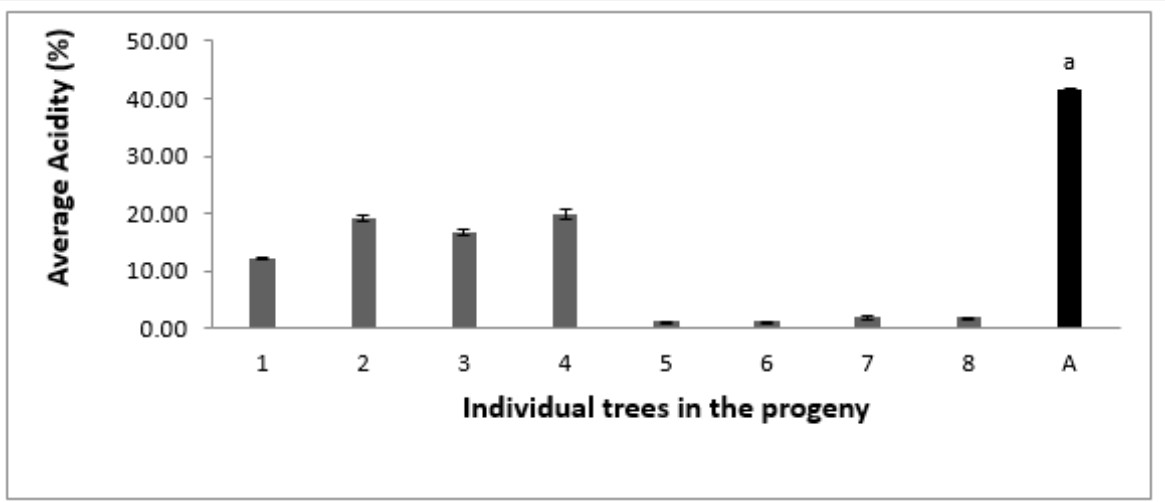

Figure 3: POA of progeny LM 16844. a: acidity of the most acid genitor in the set of genitors analyzed.

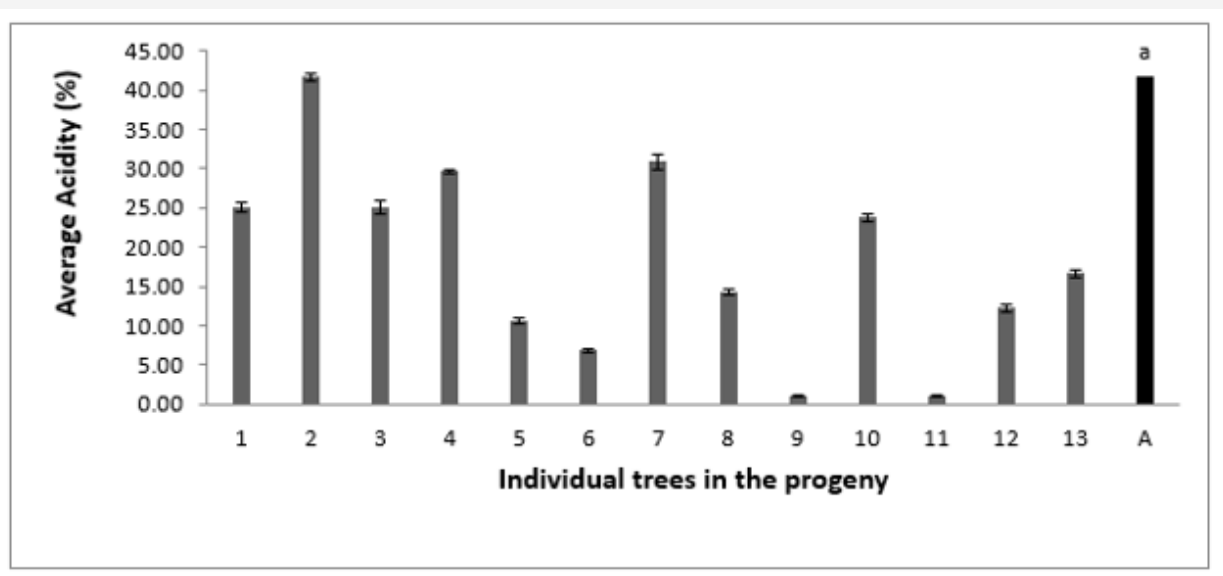

Figure 4: POA of progeny LM 19121. a: acidity of the most acid genitor in the set of genitors analyzed.

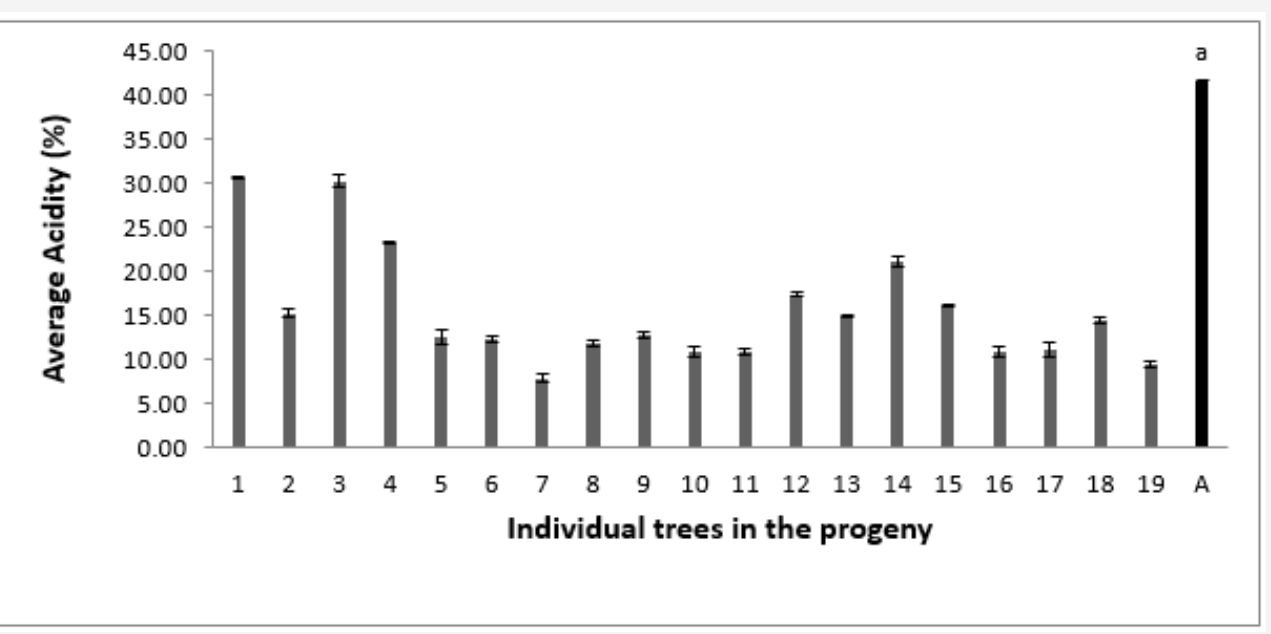

Figure 5: POA of the progeny LM 17685. a: acidity of the most acid genitor in the set of genitors analyzed.

In progeny LM 17689 from the cross between LM 3038D and LM 3034D, the 19 genitors analyzed produced oil with high acidity, i.e. $100 \%$ high acidity of palm oil in the progeny. The acidity values varied between 7.79 and 30.61\% (Figure 5). Genitors 7 and 19 produced oil with average acidity. In progeny LM 16598 from the cross LM 3043D x LM 3038D, the 14 genitors analyzed produced oil with high acidity, i.e. $100 \%$ high acidity of palm oil in the progeny. The different acidity values varied between $8.43 \%$ and $20.27 \%$ (Figure 6). Only genitor 8 produced oil with average acidity. The LM 17204 progeny comes from the cross LM 2523D x LM 2531D. For a total of 27 genitors analyzed, 25 produced high acidity oil and 2 produced low acidity oil. The proportions obtained were as follows: $92.52 \%$ for high acidity and $7.48 \%$ for low acidity of palm oil (Figure 7). Five genitors produced oil with average acidity. Progeny LM 18175 originates from the cross LM 5155D x LM 5100D. For a total of 28 genitors analyzed, 100\% high acidity was obtained. The acidity values of palm oil varied from $6.57 \%$ to $43 \%$ (Figure 8 ). Six genitors produced oil with average acidity. Progeny LM 18175 comes from the cross LM 5216D x LM 5100D. For a total of 14 genitors analyzed, only 2 were low acidity palms. The acidity varied from $0.71 \%$ to $29.51 \%$ (Figure 9). Genitor No 1 and 5 produced CPO with average acidity. Progeny LM 18668 comes from the self- 
fertilization of LM 2515D. For a total of 33 genitors analyzed, only 8 low acidity individuals were obtained. The acidity values of palm oil vary from $0.96 \%$ to $34 \%$ (Figure 10). Genitor No 6, 14, 20 and 24 produced oil with average acidity. Progeny LM 17163 originated from the cross LM 2750D x LM 2749D. For a total of 25 genitors analyzed, $100 \%$ high acidity was obtained. The acidity values of palm oil ranged from $7.07 \%$ to $29.51 \%$ (Figure 11 ). Only genitors 15,16 and 18 produced oil with average acidity. In general, the different acidity values obtained from the 204 trees analyzed were classified as low (8.82\%), average (14.21\%) and high (77.45\%) acidity (Table 3).

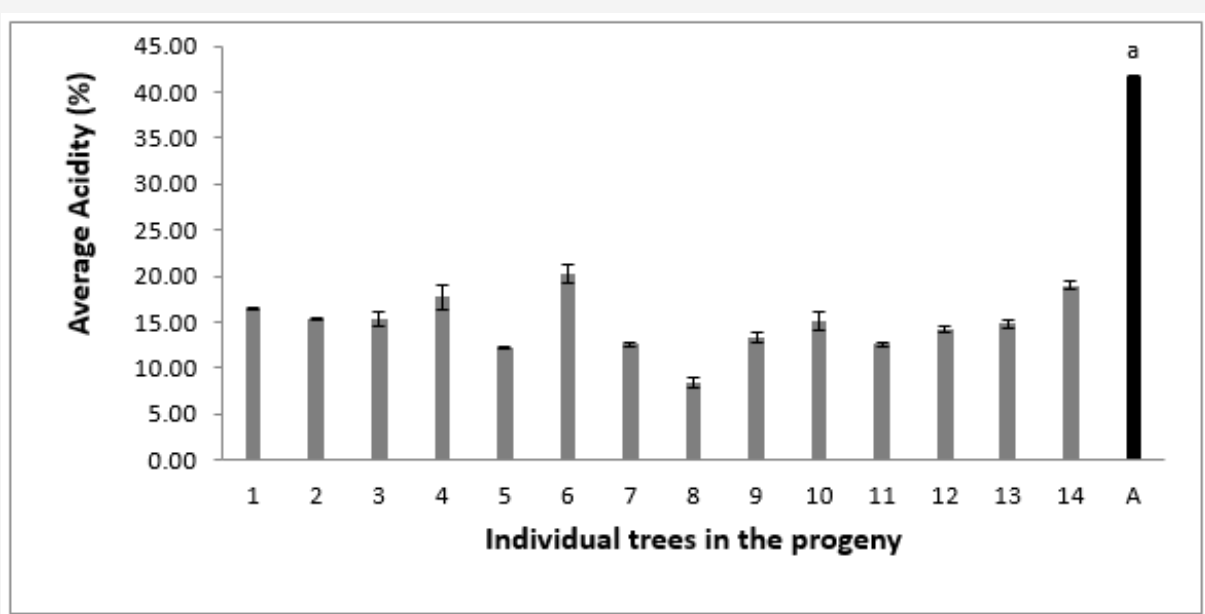

Figure 6: POA of the progeny LM 16598. a: acidity of the most acid genitor in the set of genitors analyzed.

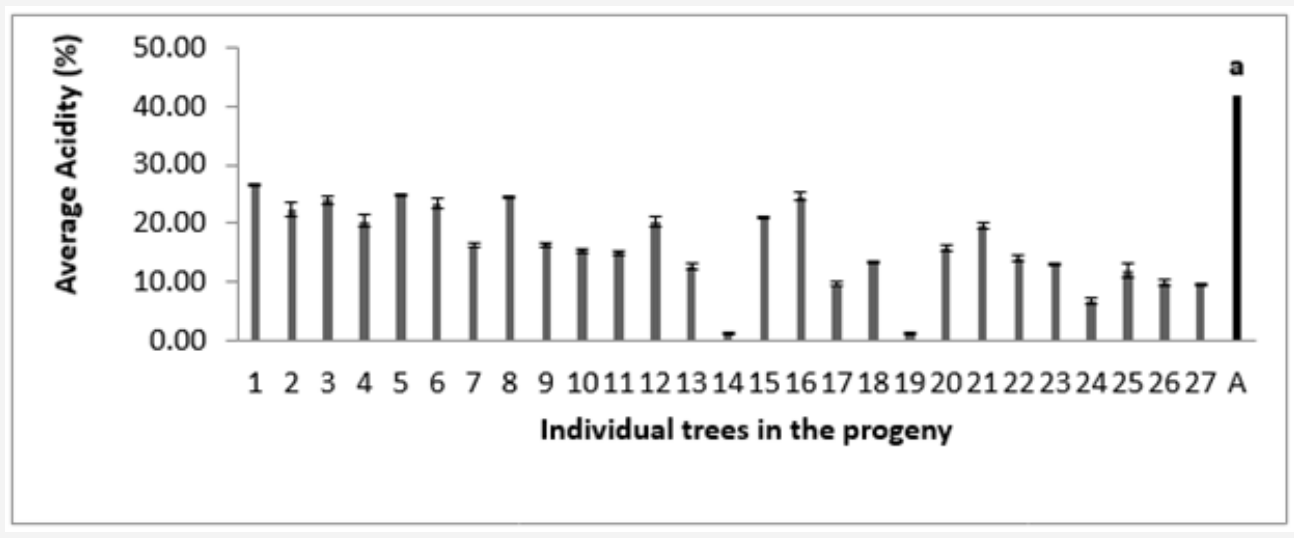

Figure 7: POA of progeny LM 17204. a: acidity of the most acid genitor in the set of genitors analyzed

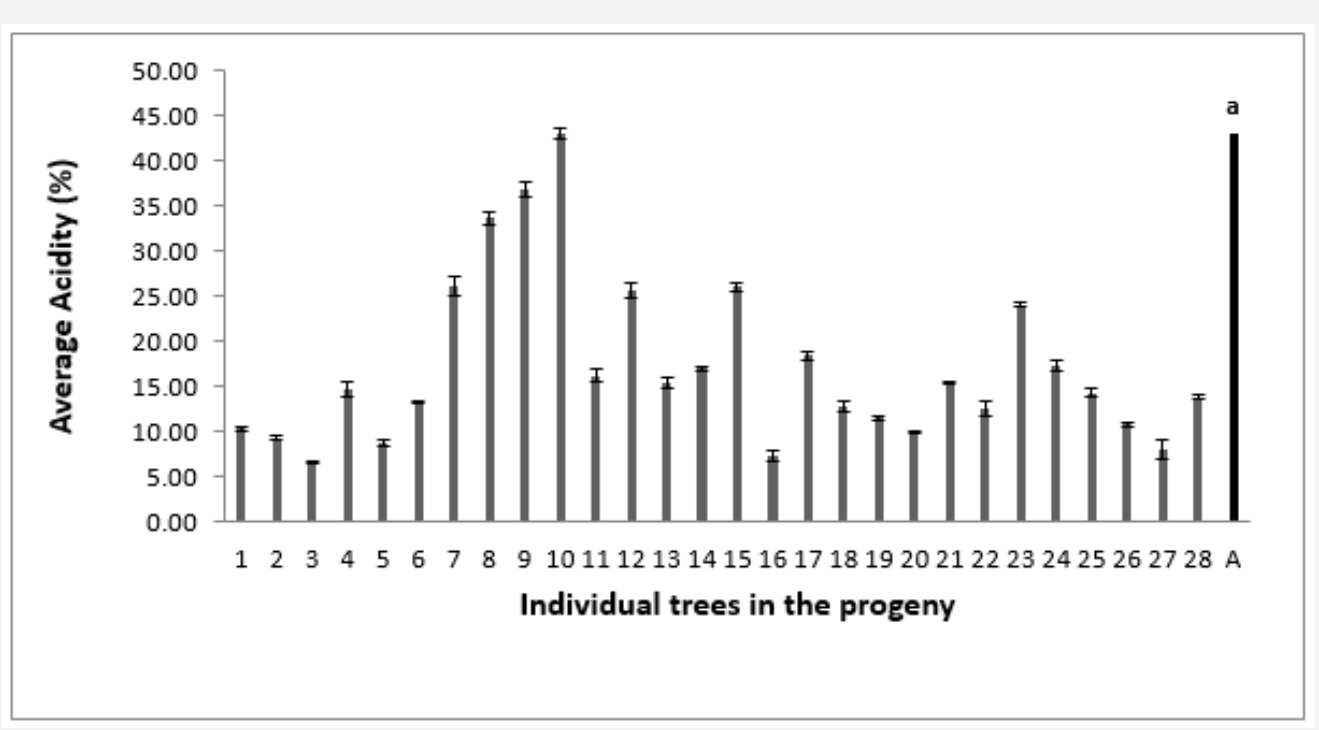

Figure 8: POA of progeny LM 181745.a: acidity of the most acid genitor in the set of genitors analyzed. 


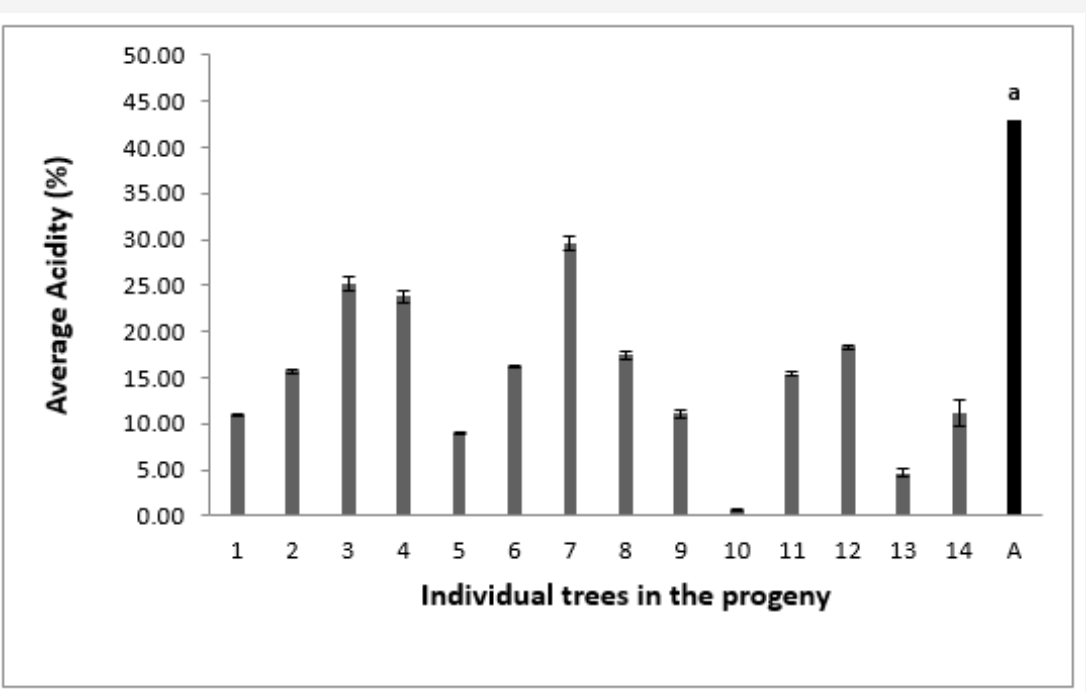

Figure 9: POA of LM 18744 progeny. a: acidity of the most acid genitor in the set of genitors analyzed.

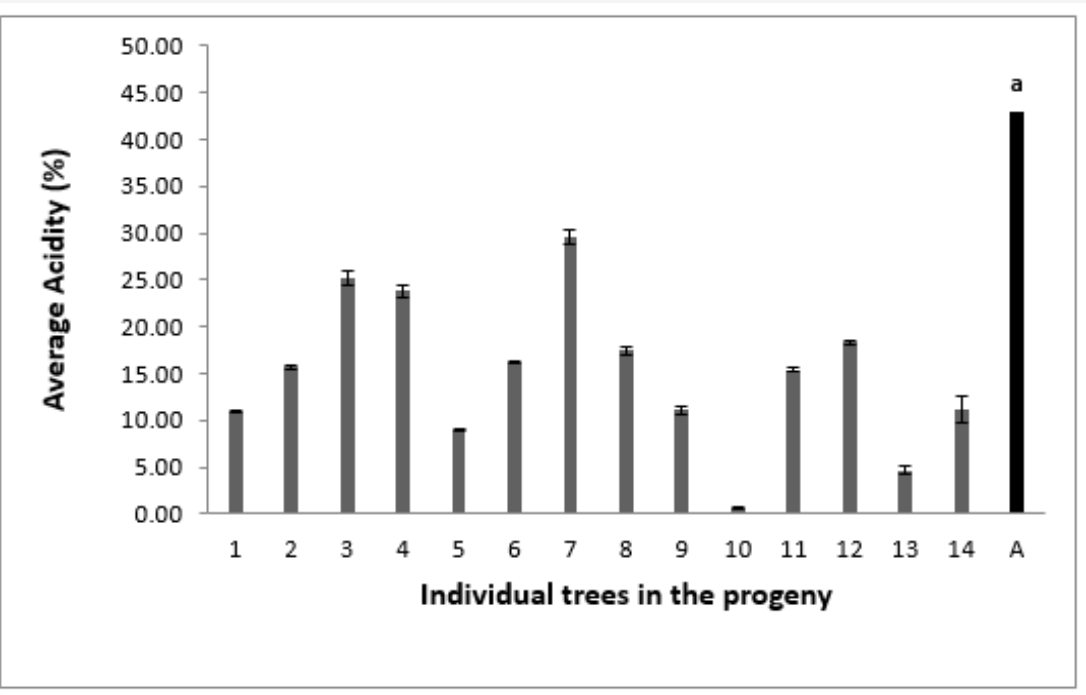

Figure 10: POA of progeny LM 18668. a: acidity of the most acid genitor in the set of genitors analyzed.

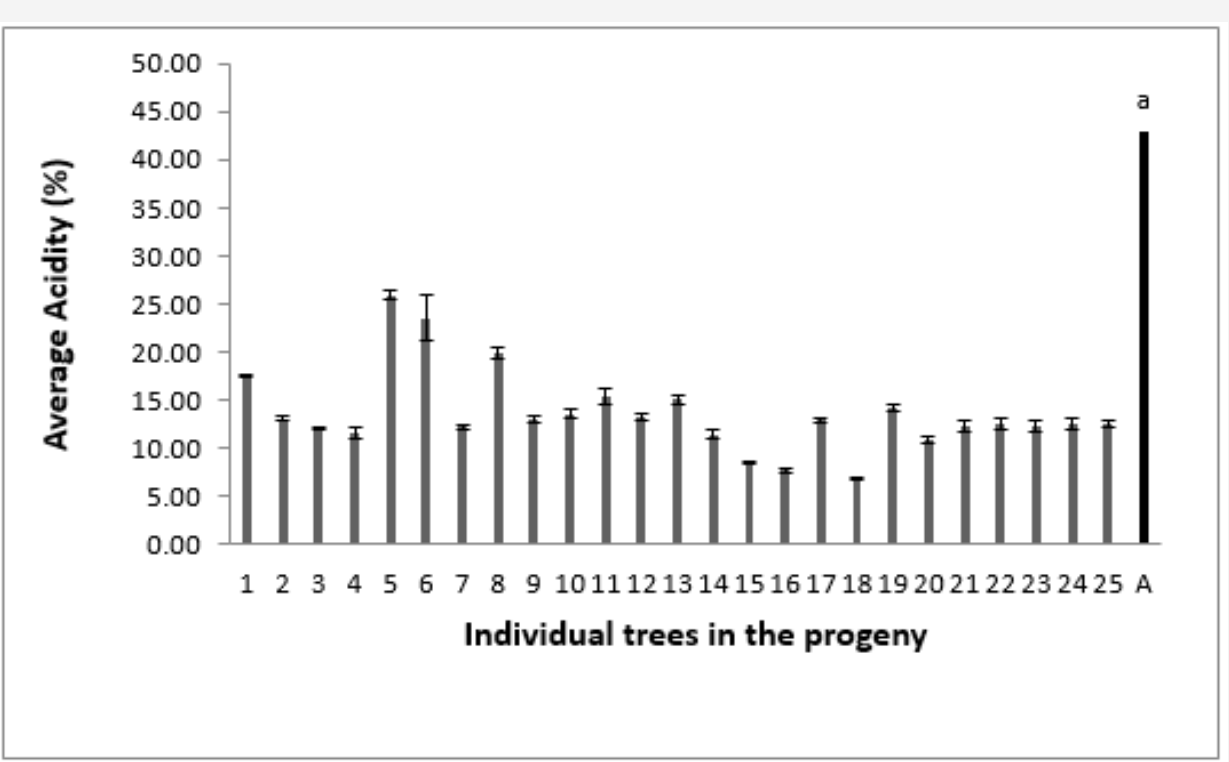

Figure 11: Acidity of progeny LM 17163. a: acidity of the most acid genitor in the set of genitors analyzed. 
Table 3: Proportions of progenies with respect to the threshold between high, low and average acidity.

\begin{tabular}{|c|c|c|c|c|}
\hline Progenies & Low Acidity & $\begin{array}{c}\text { Average } \\
\text { Acidity }\end{array}$ & $\begin{array}{c}\text { High } \\
\text { Acidity }\end{array}$ & $\begin{array}{c}\text { Total of } \\
\text { Analyzed Trees }\end{array}$ \\
\hline LM 18175 & $/$ & 6 & 22 & 28 \\
\hline LM 18688 & 8 & 4 & 21 & 33 \\
\hline LM 17685 & $/$ & 2 & 17 & 19 \\
\hline LM 18744 & 2 & 1 & 11 & 14 \\
\hline LM 19121 & 2 & 2 & 9 & 13 \\
\hline LM 17163 & $/$ & 3 & 22 & 25 \\
\hline LM 17204 & 2 & 5 & 20 & 27 \\
\hline LM 16598 & $/$ & 1 & 13 & 14 \\
\hline P0 5670 & $/$ & 2 & 9 & 11 \\
\hline P0 5669 & $/$ & 3 & 9 & 12 \\
\hline LM 16844 & 4 & $/$ & 4 & 8 \\
\hline Total & 18 & 29 & 158 & 204 \\
\hline Percentage & 8.82 & 14.21 & 77.45 & \\
\hline
\end{tabular}

\section{Discussion}

The study of palm oil acidity of CPO from individual palms shows a great variability between the progenies on the one hand and within each progeny on the other hand. From a total of 11 progenies, six were homogeneous with high oil acidity while the five others were heterogeneous. No progeny studied showed 100\% low acidity. This result is different from that of Likeng et al. [23] who obtained only 4 out of 11 progenies with $100 \%$ high acidity. This could be due to the fact that since palm acidity (PA) gene is possibly dominant, whatever the crossing, one obtains either a high-acid homogeneity or a heterogeneous progeny. The LM 18688 and LM 19121 progenies derived from self-fertilization are heterogeneous for this trait. This suggests that the LM 2515D and LM 3005D self-fertilized parents are possibly heterozygous at the locus under consideration.

In the PO $3281 \mathrm{~T}$ progeny with high acidity, the self-fertilized parent is probably homozygous at the locus concerned. The nature of this parent clearly justifies the homogeneity observed in the PO 5669 progeny resulting from the cross between PO 3281T and P0 2786P. The work of Likeng et al. [23] suggested that the gene responsible for the acidity of palm oil is monogenic with strong dominant acidity, and that a progeny is homogeneous with high acidity if and only if at least one of the crossed parents produces oil with high acidity.

Unlike the work of Ngando et al. [22], which generally presented the acidity of oil palm progenies, this study clearly shows individual variability in the acidity of palm oil from progenies derived from several combinations. This result corroborates that of Guedes [27], who showed the variability of fruit acidity of 25 plants of Jabuticaba progeny grown in a tropical climate. León et al. [26] on the one hand and Perez Vich et al. [28] on the other hand, working respectively on the variability of free fatty acids of olive oil of certain progenies derived from several genetic combinations and the heritability of elevated palmitic acid content in the CAS-12 mutant in the same species, showed the influence of crossing on free fatty acid composition.

The three classes of acidity obtained showed a great variability. The class of genitors with high acidity constituted 77\%. This result is contrary to that of Perèz Vich et al. [28] who separated olive seeds into three classes based on their oil acidity values as 19, 38 and 7 respectively for high, intermediate, and low acidity. This is partly due to the fact that the gene responsible is dominant [23]. The other reason could be the impossibility of separating the dominant homozygotes with high acidity from the heterozygotes. Such difficulties led Hiroshi et al. [29] and Pandey et al. [30] to classify fruit acidity into two classes in the study of the heritability of acidity of apple fruits and five phenotype classes of Erucic acid in Indian Mustard (Brassica juncea L. Czern \& Coss) respectively. All these observations highlight the heritability of fruit acidity in general and that of palm oil in particular, as confirmed by other studies $[29,30]$.

\section{Conclusion}

It can be retained from this and other studies that the acidity of oil palm progenies is transmissible and highly variable. Since the progenies come from crosses that produce several individuals, this work has shown that acidity depends on the genotype of each plant. Male and female progenies used in seed production contain genotypes that produce oil with high and low acidity values, each with dominance of the high acidity genotype.

Since the highly acidic oil is unfit for human consumption, the production of hybrid seeds with low acidity remains the ideal approach to enhance this product. To achieve this, a study of the individual acidity of genitors used for commercial seed production is essential, before crossing only low acid genitors between them. In perspective, this study will be extended to all the genitors used for seed production at CEREPAH in order to identify the low acidity genitors.

\section{Acknowledgement}

None.

\section{Conflict of Interest}

No conflict of interest.

\section{References}

1. Soy Stats (2016) World Vegetable Oil Consumption 2015.

2. Hirsch RD (1999) La Filière Huile de Palme au Cameroun dans use Perspective de Relance. Agence Française de Développement, Paris (France).

3. Sundram K, Sambanthamurthi R, Tan YA (2003) Palm fruit chemistry and nutrition. Asia Pacific J Clin Nutr 12(3): 355-362.

4. Corley RHV, Tinker PBH (2008) The oil palm. In: John Wiley \& Sons (eds).

5. Mancini A, Imperlini E, Nigro E, Montagnese C, Daniele A, et al. (2015) Biological and Nutritional Properties of Palm Oil and Palmitic Acid: Effects on Health Molecules 20(9): 17339-17361.

6. Tagoe SMA, Dickinson MJ, Apetorgbor MM (2012) Factors influencing quality of palm oil produced at the cottage industry level in Ghana. International Food Research Journal 19(1): 271-278. 
7. De Almeida DT, Nunes IL, Conde PL, Rosa RPS, Rogério WF, et al. (2013) A quality assessment of crude palm oil marketed in Bahia, Brazil. Grasas y Aceites 64(4): 387-394.

8. Mulindi S, Mutai EBK, Njue M, Rotich PK (2016) Influence of Duration of Heat Treatment and Screen Pore Sizes on Palm Oil Yield and Quality. Euro J Adv Engg Tech 3(8): 67-74.

9. Desassis A (1957) Palm oil acidification. Oléagineux 12: 525-534.

10. Patil KJ, Manojkumar ZC, Raghunath TM (2011) Lipase biodiversity. Indian J Sci Technol 4(8): 971-982.

11. Morcillo F, Cros D, Billote N, Ngando EGF, Domonhéro H, eta l. (2013) Improving palm oil quality through identification and mapping of the lipase causing oil deterioration. Nat Commun 4: 2160.

12. Ngando GF, Mpondo EA, Dikotto Ekewe EL, Koona P (2011) Assessment of the quality of crude palm oil from smallholders in Cameroon. J Stored Prod Postharvest Res 3: 52-58.

13. Ngando EGF, Mpondo Mpondo EA, Ewane MA (2013) Some quality parameters of crude palm oil from major markets of Douala, Cameroon. Afr J Food Sci 7(12): 473-478.

14. Goudoum A, Makambeu Ndomche A, Abdou Bouba A, Mbofung CMC (2015) Some Physicochemical Characteristics and Storage Stability of Crude Palm Oils (Elaeis guineensis Jacq). American Journal of Food Science and Technology 3(4): 97-102.

15. Gulla S, Waghray K (2011) Effect of Storage on Physico-chemical Characteristics and Fatty Acid Composition of Selected Oil Blends. JLS 3(1): 35-46.

16. Ohimain EI, Sylvester C Izah, Fawari AD (2013) Quality assessment of crude palm oil produced by semi-mechanized processor in Bayelsa state, Nigeria. J Agric Food Sci 1(11): 171-181.

17. Noviar MH, Sukardi, rifin A (2016) Quality Control System of Crude Palm Oil on Palm Oil Processing Industry (Case Study Bah Jambi Palm Oil Mill, PTPN IV, Medan, North Sumatra). IJSRP 6(7): 101-106.

18. Tombs MP, Stubbs JM (1982) The Absence of Endogenous Lipase from Oil Palm Mesocarp. J Sci Food Agric 33(9): 892-897.

19. Khan SH, Muhammad F, Idrees M, Shafique M, Hussain I, Farooqi MH (2005) Some studies on spoilage fungi of pickles. J Agri Soc Sci 1(1): 1415.
20. Okechalu JN, Dashen MM, Lar PM, Okechalu B, Gushop T (2011) Microbiological quality and chemical characteristics of palm oil sold within Jos Metropolis, Plateau State, Nigeria. J Microbiol Biotech Res 1(2): 107-112

21. Ngando Ebongue GF, Dhouib R, Carrière F, Amvam Zollo PH, Arondel $\mathrm{V}$ (2006) Assaying lipase activity from oil palm fruit (Elaeis guineensis Jacq.) mesocarp. Plant Physiology and Biochemistry 44(10): 611-617.

22. Ngando Ebongue GF, Koona P, Nouy B, Zok S, Carrière F, Zollo PHA, Arondel V (2008) Identification of oil palm breeding lines producing oils with low acid values. European Journal of Lipid Science and Technology 110(6): 505-509.

23. Likeng Li Ngue BC, Bell JM, Ngando Ebongue GF, Godswill NN, et al. (2016) Genetic determinism of oil acidity among some DELI oil palm (Elaeis guineensis Jacq.) progenies. Afr J Biotechnol 15(34): 1841-1845.

24. Sambantarmurthi R, Sundram K (2000) Chemistry and biochemistry of palm oil. Progress in lipid research 39(6): 507-558.

25. AFNOR (1988) Recueil des norms française sur les corps gras, grains oléagineuses, produits derives, ( $4^{\text {th }}$ edn). Association Française de Normalisation, Paris.

26. León L, Uceda M, Jiménez A, Martín LM, Rallo L (2004) Variability of fatty acid composition in olive (Olea europaea L.) progenies. Span J Agric Res 2(3): 353-359.

27. Guedes MNS, Rufini JCM, Azevedo AM, Pinto NAVD (2014) Fruit quality of jabuticaba progenies cultivated in a tropical climate of altitude. Fruits 69: 449-458.

28. Perez VB, Garces R, Fernandez Martinez JM (2002) Inheritance of high palmitic acid content in the sunflower mutant CAS-12 and its relationship with high oleic content. Plant Breed 121(1): 49-56.

29. Hiroshi I, Shigeki M, Nobuhiro K, Naozumi M, Sae T, et al. (2012) Mode of inheritance in fruit acidity in apple analyses with a mixed model of a major gene and polygenes using large complex pedigree. Plant Breed 131(2): 322-328.

30. Pandey S, Kabdal M, Tripathi MK (2013) Study of Inheritance of Erucic Acid in Indian Mustard (Brassica juncea L. Czern \& Coss). Octa J Biosci 1(1): 77-84. 